\title{
Type 2 diabetes: Does pancreatic fat really matter?
}

\author{
Valeria Guglielmi $^{1,2}$ (D) | Paolo Sbraccia ${ }^{1,2}$ (C)
}

${ }^{1}$ Department of Systems Medicine, University of Rome Tor Vergata, Rome, Italy

${ }^{2}$ Internal Medicine Unit and Obesity Center, University Hospital Policlinico Tor Vergata,

Rome, Italy

\section{Correspondence}

Valeria Guglielmi, Department of Systems Medicine, University of Rome "Tor Vergata", Via Montpellier 1, 00133 Rome, Italy. Email: valeria.guglielmi@uniroma2.it

\begin{abstract}
Summary
With the increasing prevalence of obesity, the interest of research in nonalcoholic fatty pancreas disease (NAFPD) has grown. Even though the pancreas appears more susceptible to lipid accumulation compared with the liver, NAFPD has been less investigated due to the limits in detecting techniques. Several definitions and synonyms for NAFPD are used by authors and can be misleading. This, together with differences in methodology and ethnicity, make the integration and comparison of studies on this topic challenging. NAFPD could be used as an early indicator of ectopic fat deposition, which is recognized as a key factor of obesity cardio-metabolic complications. However, evidence that NAFPD has a pathogenetic role in type 2 diabetes is also emerging. This article reviews the current state of knowledge on the clinical and pathophysiologic relevance of NAFPD in $\beta$-cell function and insulin resistance.
\end{abstract}

\section{KEYWORDS}

ectopic fat depots, nonalcoholic fatty liver disease, pancreatic fat, pancreatic steatosis, type 2 diabetes, $\beta$-cell dysfunction

\section{1 | INTRODUCTION}

The global epidemic of obesity may largely explain the concurrent increase in the incidence and prevalence of type 2 diabetes (T2DM) over the last decades.

Therefore, the study of adipose tissue biology has gained an enormous research interest. This has gradually transformed adipose tissue from an inert lipid store into a metabolically dynamic endocrine organ capable of synthesizing biologically active compounds involved in metabolic homeostasis, as well as in many biological functions. $^{1-3}$

Although the epidemiological association between obesity and T2DM in general is well described, ${ }^{4}$ the evidence of pathophysiological connection between them has been fully appreciated only in recent years. This issue has raised even more attention because of accumulating evidence that also a modest weight loss, induced by dietary interventions, ${ }^{5,6}$ physical exercise, ${ }^{7,8}$ and drugs and bariatric surgery procedures, ${ }^{9,10}$ is capable of significantly reducing T2DM risk and improving glycemic control.

Statement of human and animal rights. This article does not contain any studies with human or animal subjects performed by the any of the authors.

\section{I THE CAUSAL LINK BETWEEN OBESITY AND TYPE 2 DIABETES}

Genome-wide association scans (GWAS) and candidate gene approaches have so far identified $\sim 40$ genes associated with T2DM and a similar number, but different, with obesity. ${ }^{11,12}$ Most of T2DM genes appear related to $\beta$-cell dysfunction, with many fewer involved in pathways related to insulin resistance independent of adiposity. ${ }^{13}$ However, the identified genes are estimated to predict only $15 \%$ of T2DM. ${ }^{14}$ This low predictive power may reflect the importance of environmental factors and epigenetic or gene-environment interactions that are not detected by population genetics-based methods.

Chronic positive energy balance, by promoting deposition of triglycerides and intermediates of lipid metabolism such as diacylglycerol and Acyl-CoA in adipose and non adipose tissues, triggers harmful cellular responses including activation of inflammatory signalling pathways, mitochondrial dysfunction, and endoplasmic reticulum and oxidative stresses. ${ }^{15}$ This cascade of lipotoxic damage in adipose tissue recruits and activates immune cells, mainly represented by macrophages, which further increase local inflammation ${ }^{16}$ and orchestrate the detrimental adaptive responses of adipose tissue. ${ }^{17}$ These responses, collectively with those taking place in the liver and skeletal muscle, the classical target organs of insulin, contribute to the pathogenesis of insulin resistance which is the key element of obesityrelated metabolic derangements. 
Initially, insulin resistance can be overcome by an increased insulin production by the pancreas, resulting in hyperinsulinemia. Afterwards, during the progression towards overt T2DM, $\beta$-cell failure to compensate adequately the greater insulin requirements occurs. ${ }^{18-20}$ The common dysfunctional $\beta$-cell phenotype in T2DM is characterized by diminished glucose sensing, increased basal insulin secretion, blunted first-phase insulin secretory response to glucose, and increased proinsulin:insulin ratios ${ }^{21,22}$ together with a presumed decrease in insulin production. ${ }^{21}$ Having said that $\beta$-cell dysfunction could be primarily due to genetic or epigenetic predisposing factors, whether this decompensation is part of the obesity-induced metabolic derangements or secondary to hyper-functioning $\beta$-cells is unclear. ${ }^{21,23,24}$

The influence of obesity on T2DM risk is determined not only by the degree of obesity but also by distribution of fat mass. Indeed, whereas abdominal obesity confers an increased risk for T2DM, metabolic syndrome and cardiovascular disease, ${ }^{25}$ preferential fat accumulation in gluteo-femoral region confers a lower risk and, as learned from lipodystrophies, may be even protective. ${ }^{26,27}$ In addition, there are numerous ectopic fat depots that may serve specialized functions related to their neighbouring tissues, ${ }^{28-31}$ playing an emerging local pathophysiological role in obesity complications.

\section{3 | ECTOPIC LIPIDS}

As previously mentioned, when obesity develops and the circulating lipids exceed storage and metabolic capacity of adipose tissue, a progressive and abnormal retention of lipids within non-adipose tissues occurs. This process, termed "steatosis", ${ }^{32}$ may involve liver, heart, skeletal muscle and pancreas. ${ }^{33}$ Lipid droplets accumulate in the cytoplasm of cells, thus leading to cell dysfunction or death, a phenomenon called lipotoxicity. ${ }^{34}$

In human studies, intrahepatic and intramyocellular lipid content emerged as much stronger predictors of insulin resistance than circulating fatty acids, suggesting that intracellular lipids may impair insulin signalling and therefore cause insulin resistance. ${ }^{35}$ Similarly, accumulation of fat in the heart has been associated with cardiac dysfunction and heart failure, ${ }^{36}$ possibly contributing to diabetic cardiomyopathy development. ${ }^{37}$

Lipid accumulation can occur by increased uptake of FFAs, increased synthesis within the tissue involved, or reduced FFAs oxidation/disposal, although the relative contribution of these factors may vary in different physiological states and tissues. ${ }^{38}$

\section{I NONALCOHOLIC FATTY PANCREAS DISEASE}

Ogilvie coined the term "pancreatic lipomatosis" to describe the excessive storage of fat in pancreatic tissue in his human post mortem study. Thereafter, owing to the lack of distinction between the lipid accumulation within acinar and $\beta$-cells and intra-pancreatic adipocyte infiltration, the accumulation of fat in the pancreatic gland has been referred to using various synonyms, including pancreatic lipomatosis, pancreatic steatosis, fatty replacement, fatty infiltration, fatty pancreas, lipomatous pseudohypertrophy, and nonalcoholic fatty pancreas disease (NAFPD). ${ }^{39}$

Because pancreatic steatosis also occurs in nonobese individuals (that is, patients with cystic fibrosis, iron overload, viral infections, chemotherapy, and chronic alcohol abuse), ${ }^{39,40}$ Smits and van Geenen proposed that the term "NAFPD" should be reserved for pancreatic steatosis associated with obesity and metabolic syndrome, ${ }^{40}$ condition possibly reversed by weight reduction or appropriate medications. ${ }^{41,42}$ On the other hand, the term "fatty replacement" should be used for those conditions that lead to acinar cell death and irreversible replacement by adipocytes. ${ }^{40,43}$

From an epidemiologic perspective, few studies aimed to estimate the prevalence of NAFPD, which ranges from 16\% and 35\% in Asian populations. ${ }^{44-46}$ However, owing to the lack of clear definitions as well as of standard diagnostic tools, the prevalence of NAFPD in general population is so far unknown. ${ }^{47}$

\section{1 | Histology and imaging techniques}

Intracellular lipid accumulation can be demonstrated in exocrine parenchyma and islet cells by immunohistochemistry or electron microscopy. ${ }^{48,49}$ However, because the histological examination needs biopsy and can be also hampered by grading errors due to the irregular accumulation of pancreatic fat, ${ }^{50}$ pancreatic steatosis is most commonly diagnosed by means of imaging techniques.

Pancreatic steatosis presents as hyperechogenic at ultrasonography, but especially in obese patients, the pancreas is not always easily visible with this technique. In addition, pancreatic fibrosis has similar ultrasonographic features, which preclude the routine use of ultrasonography as a screening tool for lipid deposition in the pancreas. ${ }^{51}$

Computed tomography (CT) with or without contrast can also be used. The density of steatotic pancreas is similar to adipose tissue on CT scan, and the amount of pancreatic fat can be measured using Hounsfield units, correlated to the spleen, although no cutoff points have been defined yet. ${ }^{52}$

Several magnetic resonance imaging (MRI) methods have been proposed to measure lipids in the pancreas, such as phase-opposed phase, Dixon method, the spectral-spatial excitation techniques, ${ }^{53,54}$ and, more recently, the 3 -dimensional fat-water MRI method. ${ }^{55}$ However, proton magnetic resonance spectroscopy (1H-MRS) is the current gold standard for noninvasive quantification of pancreatic triacylglycerol content, being almost equivalent to histology and biochemical measurements for in vivo use. ${ }^{56}$ However, MRI and $1 \mathrm{H}-\mathrm{MRS}$ still have some limitations, including high cost, long scanning time, and susceptibility to magnetic resonance chemical shift artefact due to the surrounding visceral fat. ${ }^{57}$ In addition, sensitivity and specificity for the detection of pancreatic steatosis with these imaging techniques have not been determined yet.

\section{2 | Pathophysiology}

Animal model studies have shown that maternal obesity throughout pregnancy and lactation can induce a significant increase in markers indicative of a NAFPD phenotype, ${ }^{58}$ which only become evident when 
offspring are subsequently challenged by a post-weaning obesogenic diet, suggesting a priming effect of maternal obesity. ${ }^{59}$

In human studies, pancreatic fat content has been closely associated with increasing $\mathrm{BMI}$, insulin resistance, metabolic syndrome, and hepatic fat content. ${ }^{44}$ Whereas NAFPD frequently coexists with NAFLD, ${ }^{60}$ the association between NAFPD and visceral adiposity has been found in some ${ }^{61,62}$ but not all ${ }^{63}$ studies. The relationship between pancreatic fat content and visceral fat seems influenced by ethnicity, resulting stronger in Hispanics than African Americans. ${ }^{61}$

Of note, the pancreas seems to be more susceptible to fat deposition compared with the liver. In fact, 15 weeks of high-fat diet determined a 5-fold greater fat accumulation in pancreas compared with the liver in mice, ${ }^{48}$ and accordingly, in human obesity, the proportion of fat was found to be higher in the pancreas than in skeletal muscle and liver. ${ }^{54}$

Also, increasing age has been associated with pancreatic steatosis. Saisho et al have found that pancreatic fat content linearly increased with age throughout childhood and reached a plateau until the age of $\sim 50$ years. ${ }^{64}$ In multiple regression analyses, the variance of pancreas lipid content explained by gender and visceral adipose tissue measured with MRI was $59.2 \% .{ }^{62}$ In addition, men have a higher pancreatic fat content compared with BMI-matched women ${ }^{62}$ and the highest prevalence of NAFPD at the age of 40 to 49 years, while the prevalence of NAFPD in women was very low until menopause. ${ }^{65}$ This suggests that aging and hormonal changes have relevance to the development of NAFPD, although confirmatory studies are needed.

The accumulation of triglycerides may occur in pancreatic parenchymal tissue ${ }^{63}$ with an almost identical distribution in the exocrine and endocrine pancreas $^{66}$ or in adipocytes, ${ }^{67}$ so that $1 \mathrm{H}$-MRS measurements of lipids in the whole pancreas have been proposed as a surrogate marker for islet lipids. ${ }^{66}$ Nevertheless, the intracellular lipid accumulation has been described to precede the adipocyte infiltration. ${ }^{66}$ On the other hand, according to other authors, fat deposition in the human pancreas appears to occur mainly in interlobular septa, rather than in cells. ${ }^{68,69}$ Whether leukocyte infiltration accompanies pancreatic steatosis is also still controversial. ${ }^{43,60}$

The potential sources of lipids accumulating in the pancreas may be represented by circulating FFAs, de novo lipogenesis, and dietary fat intakes. Phospholipids turnover could also provide a source of extracellular FFAs.

\section{5 | NAFPD AND TYPE 2 DIABETES}

Some cross-sectional studies have shown that subjects with T2DM have an increased MRS-measured or MRI-measured pancreatic fat content compared with non-diabetics ${ }^{63,70,71}$ and that, in turn, subjects with NAFPD a higher proportion of T2DM than non-NAFPD group. ${ }^{44}$ In addition, NAFPD has been found associated with T2DM independent of adiposity and other cardiometabolic risk factors, ${ }^{72}$ suggesting that NAFPD might represent an additional factor other than NAFLD able to deteriorate glucose metabolism (Figure 1).

By contrast, others observed no difference in pancreatic fat measured by histology at autopsy or CT scans ${ }^{64}$ in relation to the presence of T2DM.

However, most studies were cross-sectional. To our best knowledge, the so far only one 5-year retrospective cohort study examining the longitudinal effects of pancreatic steatosis on incident T2DM in Japanese population. In this study, the association between pancreatic steatosis and increased incidence of T2DM disappeared after adjustment for potential confounders including BMI and liver attenuation, ${ }^{73}$ even if it remains to be elucidated whether these findings could be observed in longer follow-up and in other ethnic groups.

\section{1 | NAFPD and insulin resistance}

Obesity represents a common pathway for the development of NAFPD, NAFLD, and T2DM.

Concurrence of fatty pancreas and fatty liver at ultrasonography was found in $67.9 \%$ of subjects, with a negative predictive value of NAFLD in normal pancreas of $96.4 \% .^{74}$ Even in obese paediatric population, approximately $50 \%$ of patients with NAFLD and $80 \%$ of biopsy-proven nonalcoholic steatohepatitis concurrently had NAFPD. ${ }^{75}$ The positive correlation of NAFLD and fatty pancreas was also demonstrated in autopsy ${ }^{60}$ or $1 \mathrm{H}$-MRS studies. ${ }^{76}$ In addition, subjects with fatty pancreas presented a more advanced form of liver

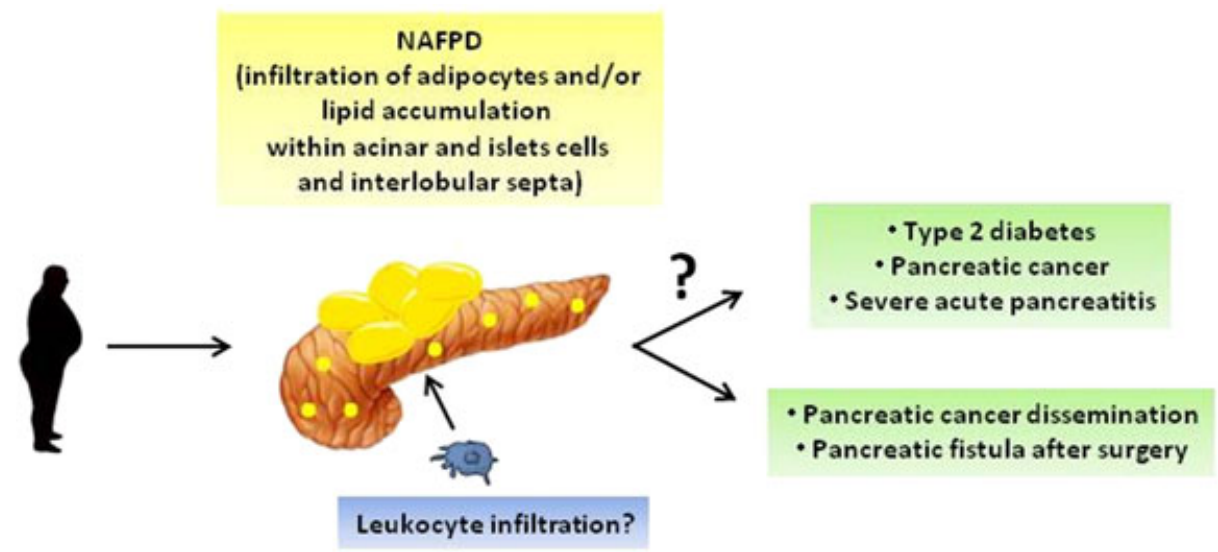

FIGURE 1 Pathophysiology and clinical consequences of nonalcoholic fatty pancreas disease, term reserved to accumulation of pancreatic fat owing to obesity and metabolic syndrome. Abbreviation: NAFPD, nonalcoholic fatty pancreas disease 
disease (reflected by higher values of fibrosis, ballooning and NAFLD Activity Score) compared with the group without NAFPD. ${ }^{75}$

The homeostasis model assessment- (HOMA-IR) and euglycemic clamp-based estimates of insulin resistance were found positively correlated with the severity of NAFPD ${ }^{74,77}$ in patients with impaired fasting glucose (IFG) and/or impaired glucose tolerance (IGT), whereas few others did not confirm these relationships in obese individuals. $^{61,62}$

Similarly, whether the association between NAFPD and insulin resistance and glucose metabolism is independent of obesity and nonalcoholic fatty liver disease is still debated. However, whereas in a community cohort study the pancreatic fat content remained significantly associated with HOMA-IR even after adjusting for liver fat and $\mathrm{BMI},{ }^{65}$ in a multivariate logistic regression analysis, this association disappeared after further adjustment for visceral fat, ${ }^{74}$ suggesting that the latter, rather than overall adiposity or pancreatic fat, does mediate the association between NAFPD and insulin resistance. In this light, NAFPD would be just part of a cluster of abnormalities during the course of obesity.

\subsection{NAFPD and $\beta$-cell dysfunction}

Several in vitro and animal studies have indicated that fatty infiltration of the pancreas contributes to a loss of $\beta$-cell mass and function. ${ }^{78,79}$ In rats, chronic exposure to high-fat diet was capable of inducing an acute inflammatory response and both acinar and islets cells damage by increasing pancreatic FFAs content. ${ }^{80}$ Accordingly, in obese Zucker prediabetic rats, the triacylglycerol content of islets preceded the development of T2DM. ${ }^{66}$

In human studies, pancreatic steatosis appears to be present and the amount of pancreatic fat an even stronger determinant of OGTT-, but not hyperglycemic clamp-, ${ }^{77}$ derived measures of impaired insulin secretion $^{56}$ than visceral fat in patients with IFG and IGT. Similarly, pancreatic lipid content, as measured by $1 \mathrm{H}-\mathrm{MRS}$, was negatively associated with oral glucose tolerance test-based measures of insulin secretion in obese nondiabetic adults, ${ }^{63}$ even if Le et al failed to confirm this correlation in obese normoglycemic adolescents, ${ }^{61}$ possibly due to more heterogeneous stages in the progression of $\beta$-cell failure in young compared with older adults. ${ }^{63}$ In fact, in children with a rare mutation in carboxyl-ester lipase, pancreatic steatosis reflects early events in the pathogenesis of diabetes.
Although, as said, many authors have emphasized an upward trend in pancreatic fat content during the progression of diabetic state, ${ }^{81,82}$ the majority of the studies could not demonstrate associations between NAFPD and overt T2DM. ${ }^{63,64}$ In line with this, no relationship between pancreatic fat and the first phase insulin response to oral glucose challenge was found regardless of glucose tolerance status. ${ }^{83}$ Therefore, on the basis of current evidence, several authors conclude that pancreatic steatosis is probably not a cause of lipotoxicity in pancreatic $\beta$-cells, but merely a marker of $\beta$-cell dysfunction. ${ }^{33,40,84}$

In this context, as explanation for the lack of association between pancreatic fat and $\beta$-cell dysfunction in diabetic patients, it has been theorized that once T2DM occurs, other factors superimposing the effect of pancreatic steatosis may rather account for the progressive decline in $\beta$-cell function. ${ }^{63}$ Namely, owing to many deleterious cascades, including oxidative stress, inflammation, apoptosis, and islets hypoperfusion, deterioration of $\beta$-cell functioning may develop at a rate disproportional to that of pancreatic fat accumulation. ${ }^{63}$ Instead, in prediabetes, lipid metabolites and adipocyte secretory products, ${ }^{85}$ whose concentration is likely high in the proximity of the islets, could contribute more blatantly to the progression of $\beta$-cell dysfunction (Figure 2).

Regardless of the causality issue, in the effort to find an explanation for the higher pancreatic fat content observed in diabetics relative to nondiabetics, it has been postulated that, once diabetes develops, fatty replacement of damaged tissue may contribute to the extra-islet pancreatic fat deposition. ${ }^{63}$ Alternatively, the increased levels of malonyl coenzyme A caused by hyperglycemia may inhibit carnitine palmitoyltransferase 1 , decreasing mitochondrial $\beta$ oxidation and, thus, further stimulating intracellular lipid accumulation ${ }^{86}$ (Figure 3).

\section{I OTHER POTENTIAL CLINICAL CONSEQUENCES OF NAFPD}

As suggested by prospective observational studies investigating the association between obesity and pancreatic cancer, ${ }^{87}$ NAFPD may promote pancreatic cancer via steatopancreatitis (NASP) and pancreatic fibrosis, a concept analogous to nonalcoholic fatty liver disease which can cause hepatic cancer via steatohepatitis and hepatic cirrhosis. ${ }^{88}$ The observation that fat mass is markedly greater in pancreatic tumours of obese mice than in lean mice supports this hypothesis. ${ }^{89}$

\section{Obesity and prediabetes}

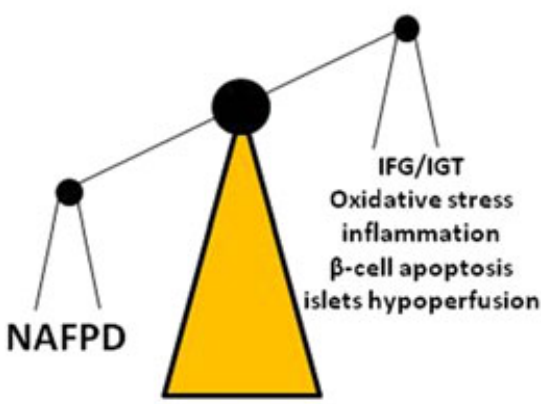

\section{Overt type 2 diabetes}

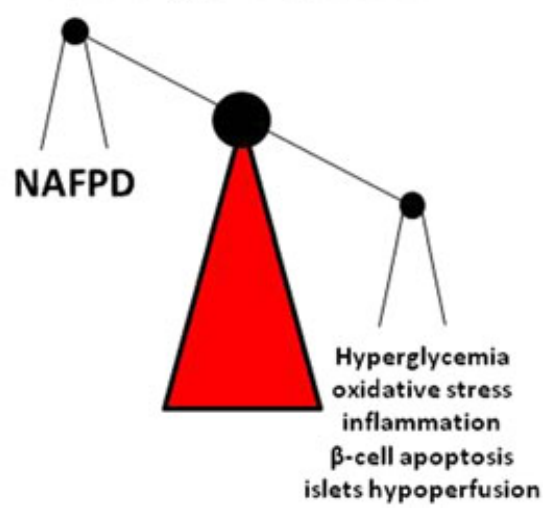

FIGURE 2 It has been theorized that once T2DM occurs, the activation of many deleterious cascades superimposing the effect of pancreatic NAFPD mostly account for the progressive decline in $\beta$-cell function, which, indeed, because then appears to develop at a rate disproportional to that of pancreatic fat accumulation. Abbreviation: NAFPD, nonalcoholic fatty pancreas disease 


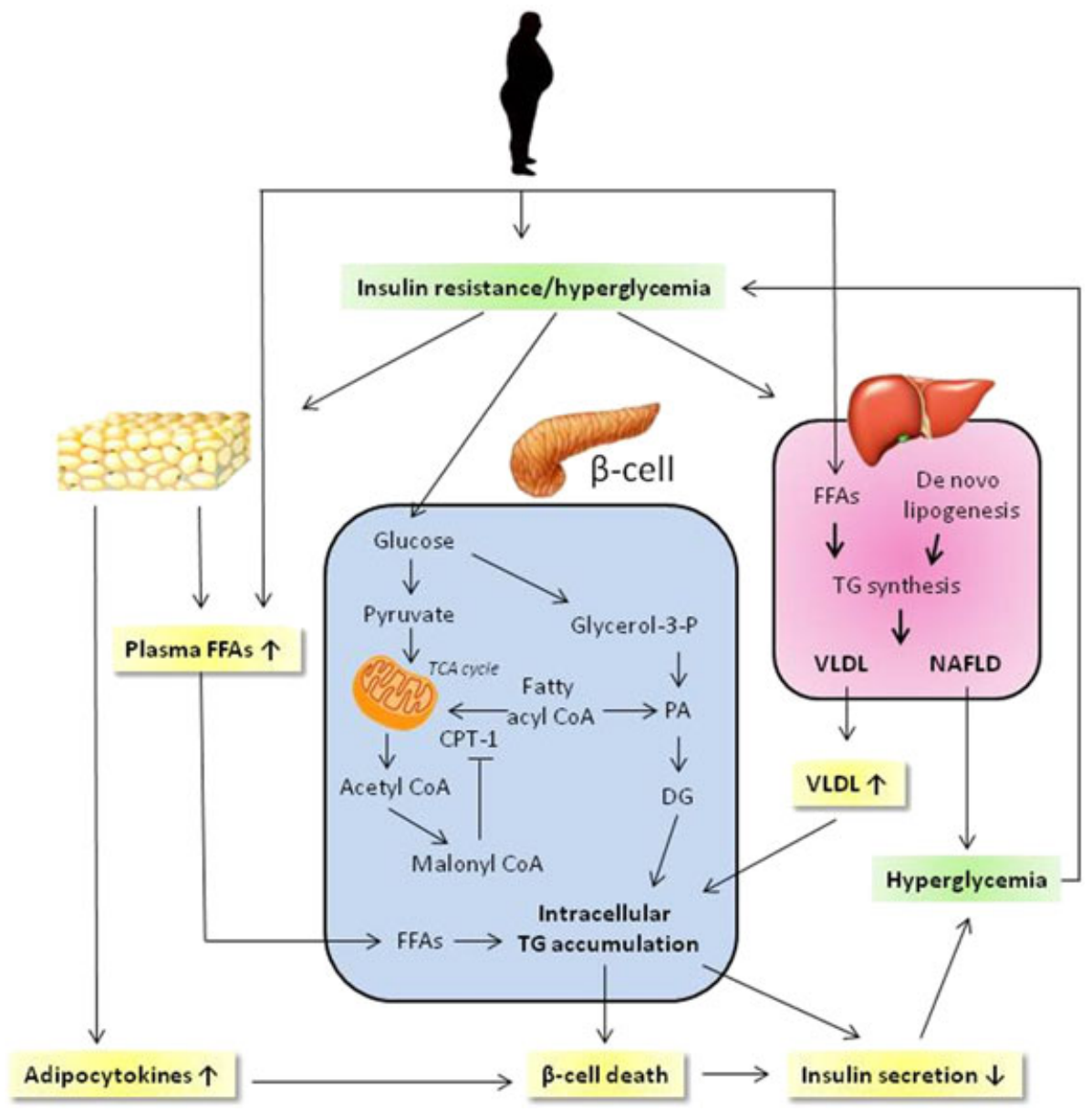

FIGURE 3 Putative interplay between nonalcoholic fatty pancreas disease and insulin resistance and $\beta$-cell dysfunction. During long-term positive energy balance, dietary fatty acids and hyperinsulinemia stimulate hepatic steatosis (NAFLD), leading to increased production and secretion of very-low-density lipoprotein (VLDL), which will increase free fatty acid (FFAs) delivery to pancreatic islets. Insulin resistance also enhances FFAs release from adipose tissue, further increasing circulating FFAs. In $\beta$-cells, chronic exposure to elevated FFAs results in increased intracellular triacylglycerol content, decreased insulin gene expression, and blunted glucose-stimulated insulin secretion. In addition, hyperglycemia inhibits carnitinine-palmitoyl transferase-1 (CPT-1) via increasing malonyl coenzyme A (malonyl CoA), thus decreasing mitochondria $\beta$-oxidation and further promoting intracellular triglyceride (TG) accumulation. This, together with adipocyte-derived inflammatory adipocitokines, contributes to $\beta$-cell destruction, further blunting insulin secretion. Abbreviations: CPT-1, carnitinine-palmitoyl transferase-1; DG, diglycerides; FFAs, free fatty acids; PA, phosphatidic acid; TCA, tricarboxylic acid; TG, triglycerides; VLDL, very-low-density lipoprotein. Modified from Yu and Wang ${ }^{47}$

However, whether pancreatic fibrosis, which can give rise to pancreatic cancer, is primarily caused by NASP or whether pancreatic cancer causes fibrosis owing to duct obstruction is unknown.

Nevertheless, in patients with pancreatic cancer, pancreatic steatosis appears to facilitate its dissemination and increases the lethality of the disease. ${ }^{67}$

Fatty pancreas may also exacerbate the severity of acute pancreatitis, ${ }^{40}$ in line with the notion that obesity is associated with developing organ failure, ${ }^{90}$ local complications, ${ }^{91}$ and increased mortality in patients with pancreatitis. ${ }^{92}$ This may occur possibly through the secretion of toxic fats and adipocitokines by pancreatic adipocytes, which create an inflammatory milieu in the pancreas, making this organ more susceptible to pancreatitis. ${ }^{93}$

Finally, pancreatic steatosis is also a risk factor for the development of pancreatic fistula after pancreatic surgery ${ }^{94,95}$ but has been shown together with obesity itself to increase the yield of pancreatic islet isolation for transplantation ${ }^{96,97}$ (Figure 1).

\section{7 | CONCLUSIONS}

With the dramatic world-wide increase in obesity prevalence, NAFPD has become object of a growing research interest. However, whereas according to in vitro and animal findings NAFPD may directly contribute to $\beta$-cell dysfunction in T2DM, current evidence in human studies remains inconclusive. As summarized by Catanzaro $\mathrm{R}$ et al, the 3 major hypotheses about NAFPD that are still to be proven, or indeed refuted, by further research are: (1) the increased amount of lipids within pancreatic $\beta$-cells can cause their dysfunction possibly through a mechanism of lipotoxicity, at least in subjects with an already impaired glucose metabolism; (2) intrapancreatic adipocytes may exert a negative paracrine effect on $\beta$-cells; and (3) NAFPD and T2DM are just both obesity consequences. ${ }^{98}$

Because contradictory findings about the relationship between NAFPD and $\beta$-cell dysfunction may possibly arise from different methods for assessing pancreatic fat content and $\beta$-cell function, as 
well as from differences in age, ethnicity, and individual liposusceptibility thresholds, additional longitudinal research is warranted to validate the role NAFPD in the development of T2DM and, hence, to unravel the underlying pathophysiology.

\section{CONFLICT OF INTEREST}

The authors declare that they have no conflict of interest.

\section{ORCID}

Valeria Guglielmi 1 http://orcid.org/0000-0002-6912-7814

Paolo Sbraccia $\odot$ http://orcid.org/0000-0001-9634-1501

\section{REFERENCES}

1. Tilg $\mathrm{H}$, Moschen AR. Adipocytokines: mediators linking adipose tissue, inflammation and immunity. Nat Rev Immunol. 2006;6:772-783.

2. Coelho M, Oliveira T, Fernandes R. Biochemistry of adipose tissue: an endocrine organ. Arch Med Sci. 2013;9:191-200.

3. Guglielmi V, D'Adamo M, Bellia A, et al. Iron status in obesity: an independent association with metabolic parameters and effect of weight loss. Nutr Metab Cardiovasc Dis. 2015;25:541-547.

4. Chan JM, Rimm EB, Colditz GA, Stampfer MJ, Willett WC. Obesity, fat distribution, and weight gain as risk factors for clinical diabetes in men. Diabetes Care. 1994;17:961-969.

5. Sacks FM, Bray GA, Carey VJ, et al. Comparison of weight-loss diets with different compositions of fat, protein, and carbohydrates. $N$ Engl J Med. 2009;360:859-873.

6. Lombardo M, Bellia A, Padua E, et al. Morning meal more efficient for fat loss in a 3-month lifestyle intervention. J Am Coll Nutr. 2014;33:198-205.

7. Jakicic JM, Otto AD. Physical activity considerations for the treatment and prevention of obesity. Am J Clin Nutr. 2005;82:226S-229S.

8. Bellia A, Salli M, Lombardo M, et al. Effects of whole body vibration plus diet on insulin-resistance in middle-aged obese subjects. Int J Sports Med. 2014;35:511-516.

9. Frikke-Schmidt H, O'Rourke RW, Lumeng CN, Sandoval DA, Seeley RJ. Does bariatric surgery improve adipose tissue function? Obes Rev. 2016;17:795-809.

10. Lombardo M, Bellia A, Mattiuzzo F, et al. Frequent follow-up visits reduce weight regain in long-term management after bariatric surgery. Bariatr Surg Pract Patient Care. 2015;10:119-125.

11. Rampersaud E, Damcott CM, Fu M, et al. Identification of novel candidate genes for type 2 diabetes from a genome-wide association scan in the Old Order Amish: evidence for replication from diabetes-related quantitative traits and from independent populations. Diabetes. 2007;56:3053-3062.

12. Hayes MG, Pluzhnikov A, Miyake K, et al. Identification of type 2 diabetes genes in Mexican Americans through genome-wide association studies. Diabetes. 2007;56:3033-3044.

13. Scherag A, Dina C, Hinney A, et al. Two new loci for body-weight regulation identified in a joint analysis of genome-wide association studies for early-onset extreme obesity in French and German study groups. PLoS Genet. 2010;6:e1000916

14. Bogardus C. Missing heritability and GWAS utility. Obesity (Silver Spring). 2009;17:209-210.

15. Hotamisligil GS, Erbay E. Nutrient sensing and inflammation in metabolic diseases. Nat Rev Immunol. 2008;8:923-934.

16. Weisberg SP, McCann D, Desai M, Rosenbaum M, Leibel RL, Ferrante AW Jr. Obesity is associated with macrophage accumulation in adipose tissue. J Clin Invest. 2003;112:1796-1808.

17. Guglielmi V, Cardellini M, Cinti F, et al. Omental adipose tissue fibrosis and insulin resistance in severe obesity. Nutr Diabetes. 2015;5:e175
18. Polonsky KS, Given BD, Hirsch L, et al. Quantitative study of insulin secretion and clearance in normal and obese subjects. J Clin Invest. 1988;81:435-441.

19. Butler AE, Janson J, Bonner-Weir S, Ritzel R, Rizza RA, Butler PC. Beta-cell deficit and increased beta-cell apoptosis in humans with type 2 diabetes. Diabetes. 2003;52:102-110.

20. Kahn SE, Hull RL, Utzschneider KM. Mechanisms linking obesity to insulin resistance and type 2 diabetes. Nature. 2006;444:840-846.

21. Kahn SE, Zraika S, Utzschneider KM, Hull RL. The beta cell lesion in type 2 diabetes: there has to be a primary functional abnormality. Diabetologia. 2009;52:1003-1012.

22. Halban PA, Polonsky KS, Bowden DW, et al. Beta-cell failure in type 2 diabetes: postulated mechanisms and prospects for prevention and treatment. Diabetes Care. 2014;37:1751-1758.

23. Leahy JL, Hirsch IB, Peterson KA, Schneider D. Targeting beta-cell function early in the course of therapy for type 2 diabetes mellitus. $J$ Clin Endocrinol Metab. 2010;95:4206-4216.

24. Wajchenberg BL. Beta-cell failure in diabetes and preservation by clinical treatment. Endocr Rev. 2007;28:187-218.

25. Coutinho T, Goel K, Correa de Sa D, et al. Central obesity and survival in subjects with coronary artery disease: a systematic review of the literature and collaborative analysis with individual subject data. J Am Coll Cardiol. 2011;57:1877-1886.

26. Lombardi F, Gullotta F, Columbaro M, et al. Compound heterozygosity for mutations in LMNA in a patient with a myopathic and lipodystrophic mandibuloacral dysplasia type A phenotype. J Clin Endocrinol Metab. 2007;92:4467-4471.

27. Guglielmi V, D'Adamo M, D'Apice MR, et al. Elbow deformities in a patient with mandibuloacral dysplasia type A. Am J Med Genet A. 2010;152A:2711-2713.

28. Guglielmi V, Maresca L, D'Adamo M, et al. Age-related different relationships between ectopic adipose tissues and measures of central obesity in sedentary subjects. PLoS One. 2014;9:e103381

29. Guglielmi V, Maresca L, Lanzillo C, et al. Relationship between regional fat distribution and hypertrophic cardiomyopathy phenotype. PLoS One. 2016;11:e0158892

30. Venteclef N, Guglielmi V, Balse E, et al. Human epicardial adipose tissue induces fibrosis of the atrial myocardium through the secretion of adipo-fibrokines. Eur Heart J. 2015;36:795-805a.

31. Addison O, Marcus RL, Lastayo PC, Ryan AS. Intermuscular fat: a review of the consequences and causes. Int $J$ Endocrinol. 2014;2014:309570

32. van Herpen NA, Schrauwen-Hinderling VB. Lipid accumulation in nonadipose tissue and lipotoxicity. Physiol Behav. 2008;94:231-241.

33. Szendroedi J, Roden M. Ectopic lipids and organ function. Curr Opin Lipidol. 2009;20:50-56.

34. Schaffer JE. Lipotoxicity: when tissues overeat. Curr Opin Lipidol. 2003;14:281-287.

35. Samuel VT, Shulman GI. Mechanisms for insulin resistance: common threads and missing links. Cell. 2012;148:852-871.

36. Guglielmi V, Sbraccia P. Epicardial adipose tissue: at the heart of the obesity complications. Acta Diabetol. 2017. https://doi.org/10.1007/ s00592-017-1020-z. [Epub ahead of print].

37. Loher H, Kreis R, Boesch C, Christ E. The flexibility of ectopic lipids. Int J Mol Sci. 2016;17(9). pii: E1554. https://doi.org/10.3390/ijms17091554

38. Shulman GI. Cellular mechanisms of insulin resistance. J Clin Invest. 2000;106:171-176.

39. Tariq H, Nayudu S, Akella S, Glandt M, Chilimuri S. Non-alcoholic fatty pancreatic disease: a review of literature. Gastroenterol Res. 2016;9:87-91.

40. Smits MM, van Geenen EJ. The clinical significance of pancreatic steatosis. Nat Rev Gastroenterol Hepatol. 2011;8:169-177.

41. Dreiling DA, Elsbach P, Schaffner F, Schwartz IL. The effect of restriction of protein and total calories on pancreatic function in obese patients. Gastroenterology. 1962;42:686-690. 
42. Jia DM, Fukumitsu KI, Tabaru A, Akiyama T, Otsuki M. Troglitazone stimulates pancreatic growth in congenitally CCK-A receptor-deficient OLETF rats. Am J Physiol Regul Integr Comp Physiol. 2001;280:R1332R1340.

43. Walters MN. Adipose atrophy of the exocrine pancreas. J Pathol Bacteriol. 1966;92:547-557.

44. Wang CY, Ou HY, Chen MF, Chang TC, Chang CJ. Enigmatic ectopic fat: prevalence of nonalcoholic fatty pancreas disease and its associated factors in a Chinese population. J Am Heart Assoc. 2014;3: e000297

45. Lesmana CR, Pakasi LS, Inggriani S, Aidawati ML, Lesmana LA. Prevalence of non-alcoholic fatty pancreas disease (NAFPD) and its risk factors among adult medical check-up patients in a private hospital: a large cross sectional study. BMC Gastroenterol. 2015;15:174

46. Zhou J, Li ML, Zhang DD, et al. The correlation between pancreatic steatosis and metabolic syndrome in a Chinese population. Pancreatology. 2016;16:578-583.

47. Yu TY, Wang CY. Impact of non-alcoholic fatty pancreas disease on glucose metabolism. J Diabetes Investig. 2017. https://doi.org/ 10.1111/jdi.12665. [Epub ahead of print].

48. Pinnick KE, Collins SC, Londos C, Gauguier D, Clark A, Fielding BA. Pancreatic ectopic fat is characterized by adipocyte infiltration and altered lipid composition. Obesity (Silver Spring). 2008;16:522-530.

49. Cnop M, Hannaert JC, Hoorens A, Eizirik DL, Pipeleers DG. Inverse relationship between cytotoxicity of free fatty acids in pancreatic islet cells and cellular triglyceride accumulation. Diabetes. 2001;50:17711777.

50. Matsumoto S, Mori H, Miyake $\mathrm{H}$, et al. Uneven fatty replacement of the pancreas: evaluation with CT. Radiology. 1995;194:453-458.

51. Schneider K, Harms K, Fendel H. The increased echogenicity of the pancreas in infants and children: the white pancreas. Eur J Pediatr. 1987;146:508-511.

52. Katz DS, Hines J, Math KR, Nardi PM, Mindelzun RE, Lane MJ. Using $\mathrm{CT}$ to reveal fat-containing abnormalities of the pancreas. AJR Am J Roentgenol. 1999;172:393-396.

53. Schwenzer NF, Machann J, Martirosian P, et al. Quantification of pancreatic lipomatosis and liver steatosis by MRI: comparison of in/ opposed-phase and spectral-spatial excitation techniques. Invest Radiol. 2008;43:330-337

54. Kovanlikaya A, Mittelman SD, Ward A, Geffner ME, Dorey F, Gilsanz V. Obesity and fat quantification in lean tissues using three-point Dixon MR imaging. Pediatr Radiol. 2005;35:601-607.

55. Hu HH, Kim HW, Nayak KS, Goran MI. Comparison of fat-water MRI and single-voxel MRS in the assessment of hepatic and pancreatic fat fractions in humans. Obesity (Silver Spring). 2010;18:841-847.

56. Heni M, Machann J, Staiger $\mathrm{H}$, et al. Pancreatic fat is negatively associated with insulin secretion in individuals with impaired fasting glucose and/or impaired glucose tolerance: a nuclear magnetic resonance study. Diabetes Metab Res Rev. 2010;26:200-205.

57. Al-Mrabeh A, Hollingsworth KG, Steven S, Tiniakos D, Taylor R. Quantification of intrapancreatic fat in type 2 diabetes by MRI. PLoS One. 2017;12:e0174660

58. Oben JA, Patel T, Mouralidarane A, et al. Maternal obesity programmes offspring development of non-alcoholic fatty pancreas disease. Biochem Biophys Res Commun. 2010;394:24-28.

59. Carter R, Mouralidarane A, Soeda J, et al. Non-alcoholic fatty pancreas disease pathogenesis: a role for developmental programming and altered circadian rhythms. PLoS One. 2014;9:e89505

60. van Geenen EJ, Smits MM, Schreuder TC, van der Peet DL, Bloemena $\mathrm{E}$, Mulder CJ. Nonalcoholic fatty liver disease is related to nonalcoholic fatty pancreas disease. Pancreas. 2010;39:1185-1190.

61. Le KA, Ventura EE, Fisher JQ, et al. Ethnic differences in pancreatic fat accumulation and its relationship with other fat depots and inflammatory markers. Diabetes Care. 2011;34:485-490.
62. Rossi AP, Fantin F, Zamboni GA, et al. Predictors of ectopic fat accumulation in liver and pancreas in obese men and women. Obesity (Silver Spring). 2011;19:1747-1754.

63. Tushuizen ME, Bunck MC, Pouwels PJ, et al. Pancreatic fat content and beta-cell function in men with and without type 2 diabetes. Diabetes Care. 2007;30:2916-2921.

64. Saisho Y, Butler AE, Meier JJ, et al. Pancreas volumes in humans from birth to age one hundred taking into account sex, obesity, and presence of type-2 diabetes. Clin Anat. 2007;20:933-942.

65. Wong VW, Wong GL, Yeung DK, et al. Fatty pancreas, insulin resistance, and beta-cell function: a population study using fat-water magnetic resonance imaging. Am J Gastroenterol. 2014;109:589-597.

66. Lee Y, Lingvay I, Szczepaniak LS, Ravazzola M, Orci L, Unger RH. Pancreatic steatosis: harbinger of type 2 diabetes in obese rodents. Int J Obes (Lond). 2010;34:396-400.

67. Mathur A, Zyromski NJ, Pitt HA, et al. Pancreatic steatosis promotes dissemination and lethality of pancreatic cancer. J Am Coll Surg. 2009;208:989-994. discussion 994-986

68. Isserow JA, Siegelman ES, Mammone J. Focal fatty infiltration of the pancreas: MR characterization with chemical shift imaging. AJR Am J Roentgenol. 1999;173:1263-1265.

69. Nghiem DD, Olson PR, Ormond D. The "fatty pancreas allograft": anatomopathologic findings and clinical experience. Transplant Proc. 2004;36:1045-1047.

70. Lingvay I, Esser V, Legendre JL, et al. Noninvasive quantification of pancreatic fat in humans. J Clin Endocrinol Metab. 2009;94:4070-4076.

71. Steven S, Hollingsworth KG, Small PK, et al. Weight loss decreases excess pancreatic triacylglycerol specifically in type 2 diabetes. Diabetes Care. 2016;39:158-165.

72. Ou HY, Wang CY, Yang YC, Chen MF, Chang CJ. The association between nonalcoholic fatty pancreas disease and diabetes. PLoS One. 2013;8:e62561

73. Yamazaki H, Tsuboya T, Katanuma A, et al. Lack of independent association between fatty pancreas and incidence of type 2 diabetes: 5-year Japanese cohort study. Diabetes Care. 2016;39:1677-1683.

74. Lee JS, Kim SH, Jun DW, et al. Clinical implications of fatty pancreas: correlations between fatty pancreas and metabolic syndrome. World J Gastroenterol. 2009;15:1869-1875.

75. Della Corte C, Mosca A, Majo F, et al. Nonalcoholic fatty pancreas disease and nonalcoholic fatty liver disease: more than ectopic fat. Clin Endocrinol (Oxf). 2015;83:656-662.

76. Hannukainen JC, Borra R, Linderborg K, et al. Liver and pancreatic fat content and metabolism in healthy monozygotic twins with discordant physical activity. J Hepatol. 2011;54:545-552.

77. van der Zijl NJ, Goossens GH, Moors CC, et al. Ectopic fat storage in the pancreas, liver, and abdominal fat depots: impact on beta-cell function in individuals with impaired glucose metabolism. J Clin Endocrinol Metab. 2011;96:459-467.

78. Kharroubi I, Ladriere L, Cardozo AK, Dogusan Z, Cnop M, Eizirik DL. Free fatty acids and cytokines induce pancreatic beta-cell apoptosis by different mechanisms: role of nuclear factor-kappaB and endoplasmic reticulum stress. Endocrinology. 2004;145:5087-5096.

79. Shimabukuro M, Higa M, Zhou YT, Wang MY, Newgard CB, Unger RH. Lipoapoptosis in beta-cells of obese prediabetic fa/fa rats. Role of serine palmitoyltransferase overexpression. J Biol Chem. 1998;273:3248732490.

80. Zhang X, Cui Y, Fang L, Li F. Chronic high-fat diets induce oxide injuries and fibrogenesis of pancreatic cells in rats. Pancreas. 2008;37:e31-e38.

81. Stamm BH. Incidence and diagnostic significance of minor pathologic changes in the adult pancreas at autopsy: a systematic study of 112 autopsies in patients without known pancreatic disease. Hum Pathol. 1984:15:677-683.

82. Chai J, Liu P, Jin E, et al. MRI chemical shift imaging of the fat content of the pancreas and liver of patients with type 2 diabetes mellitus. Exp Ther Med. 2016;11:476-480. 
83. Begovatz P, Koliaki C, Weber K, et al. Pancreatic adipose tissue infiltration, parenchymal steatosis and beta cell function in humans. Diabetologia. 2015;58:1646-1655.

84. van Raalte $\mathrm{DH}$, van der Zijl NJ, Diamant M. Pancreatic steatosis in humans: cause or marker of lipotoxicity? Curr Opin Clin Nutr Metab Care. 2010;13:478-485.

85. Zhao YF, Feng DD, Chen C. Contribution of adipocyte-derived factors to beta-cell dysfunction in diabetes. Int J Biochem Cell Biol. 2006;38:804-819.

86. Rasmussen BB, Holmback UC, Volpi E, Morio-Liondore B, PaddonJones D, Wolfe RR. Malonyl coenzyme A and the regulation of functional carnitine palmitoyltransferase- 1 activity and fat oxidation in human skeletal muscle. J Clin Invest. 2002;110:1687-1693.

87. Larsson SC, Orsini N, Wolk A. Body mass index and pancreatic cancer risk: a meta-analysis of prospective studies. Int $J$ Cancer. 2007;120:1993-1998.

88. Patel AV, Rodriguez C, Bernstein L, Chao A, Thun MJ, Calle EE. Obesity, recreational physical activity, and risk of pancreatic cancer in a large $\mathrm{U}$. S. cohort. Cancer Epidemiol Biomarkers Prev. 2005;14:459-466.

89. Zyromski NJ, Mathur A, Pitt HA, et al. Obesity potentiates the growth and dissemination of pancreatic cancer. Surgery. 2009;146:258-263.

90. Lankisch PG, Schirren CA. Increased body weight as a prognostic parameter for complications in the course of acute pancreatitis. Pancreas. 1990;5:626-629.

91. Suazo-Barahona J, Carmona-Sanchez R, Robles-Diaz G, et al. Obesity: a risk factor for severe acute biliary and alcoholic pancreatitis. Am J Gastroenterol. 1998;93:1324-1328.
92. Martinez J, Johnson CD, Sanchez-Paya J, de Madaria E, Robles-Diaz G, Perez-Mateo M. Obesity is a definitive risk factor of severity and mortality in acute pancreatitis: an updated meta-analysis. Pancreatology. 2006;6:206-209.

93. Frossard JL, Lescuyer P, Pastor CM. Experimental evidence of obesity as a risk factor for severe acute pancreatitis. World J Gastroenterol. 2009;15:5260-5265.

94. Mathur A, Pitt HA, Marine M, et al. Fatty pancreas: a factor in postoperative pancreatic fistula. Ann Surg. 2007;246:1058-1064.

95. Gaujoux S, Cortes A, Couvelard A, et al. Fatty pancreas and increased body mass index are risk factors of pancreatic fistula after pancreaticoduodenectomy. Surgery. 2010;148:15-23.

96. Kaddis JS, Danobeitia JS, Niland JC, Stiller T, Fernandez LA. Multicenter analysis of novel and established variables associated with successful human islet isolation outcomes. Am J Transplant. 2010;10:646-656.

97. Hanley SC, Paraskevas S, Rosenberg L. Donor and isolation variables predicting human islet isolation success. Transplantation. 2008;85:950-955.

98. Catanzaro R, Cuffari B, Italia A, Marotta F. Exploring the metabolic syndrome: nonalcoholic fatty pancreas disease. World J Gastroenterol. 2016;22:7660-7675.

How to cite this article: Guglielmi V, Sbraccia P. Type 2 diabetes: Does pancreatic fat really matter? Diabetes Metab Res Rev. 2017:e2955. https://doi.org/10.1002/dmrr.2955 